\title{
Research on C30 Concrete Mix Proportion in Guangdong Province
}

\author{
Guangxing Lai ${ }^{*}$, Jianli Yin ${ }^{1}$, Junhui $\mathrm{Ye}^{1}$, Yujia Chen ${ }^{1}$ and Wei Xiao ${ }^{1}$ \\ ${ }^{1}$ KZJ New Materials Group Co., Ltd. Xiamen 361101, Fujian, China
}

\begin{abstract}
The reasons of $\mathrm{C} 30$ concrete bleeding in winter in Guangdong province were studied by collecting the concrete mix proportions of $\mathrm{C} 30$ concrete mixing plants in Guangdong, Fujian, Henan, Hunan, Chongqing and Shaanxi regions, the difference between the concrete mix proportions in Guangdong and other regions was investigated. Based on the representative concrete mix proportion in Guangdong province, the concrete bleeding water test was carried out, and the correlation between the amount of different cementing materials and the bleeding rate was investigated. The results showed that compared with other regions, the $\mathrm{C} 30$ concrete mix proportion in Guangdong has the lowest total cementitious material, which made it more prone to bleeding. The amount of slag powder and the total amount of cementitious materials have a high correlation with the bleeding rate. With the increase of the amount of slag powder and the total amount of cementitious materials, the bleeding rate decreases.
\end{abstract}

\section{Foreword}

With the rapid economic development, especially the rise of the housing industry, the amount of commercial concrete has increased exponentially. In the concrete production process, the concrete mix proportion used is very important.concrete mix proportion refers to the combination of cement, water, coarse and fine aggregates, admixtures and mineral admixtures to obtain a concrete formula that meets engineering requirements and conforms to specifications. The quality of concrete mix proportion has a direct impact on the smooth construction of concrete, the quality of concrete works and the cost of concrete works. In terms of the study of concrete mix proportion, more work has been done at home and abroad ${ }^{[1-6]}$.

\section{Experimental Part}

\subsection{Test raw Materials}

Cement(C): Flying Deer brand P.O 42.5 cement; Fly ash(F): II level; Slag powder(K): Grade S95; Fine aggregate(S): river sand whose fineness modulus is $2.6 \sim$ 2.9 and whose silt content is less than $1 \%$; Coarse aggregate $(G)$ : continuous graded crushed stone with nominal diameter of $5 \mathrm{~mm} 20 \mathrm{~mm}$; Standard polycarboxylate superplasticizer: $50 \%$ solid, commercially available.

\subsection{Performance Test}

Concrete test: Refer to GB/T 50080-2016 "Standard for Performance Test Methods of General Concrete Mixtures" and GB/T 50081-2019 "Standard for Test Methods of Physical and Mechanical Properties of Concrete " respectively.

\section{Results and discussion}

\subsection{Mix proportion collection and analysis}

The C30 concrete mix proportions of 6 regions in Guangdong, Fujian, Henan, Hunan, Chongqing and Shaanxi were collected. 70 concrete mix proportions were collected in each region, totaling 420 concrete mix proportions.

The average concrete mix proportion values of various regions were calculated, and the results are shown in Table 1.

Table 1. Average concrete mix proportion in various regions

\begin{tabular}{|c|c|c|c|c|c|c|}
\hline \multirow{2}{*}{ Region } & \multicolumn{5}{|c|}{ Concrete mix proportion/ (kg/m3) } \\
\cline { 2 - 7 } & C & F & K & S & G & W \\
\hline Guangdong & 169 & 74 & 76 & 793 & 1067 & 157 \\
\hline Shaanxi & 283 & 67 & 17 & 829 & 1039 & 162 \\
\hline Chongqing & 224 & 61 & 53 & 884 & 1003 & 160 \\
\hline
\end{tabular}

\footnotetext{
* Corresponding author: lgx502@foxmail.com
} 


\begin{tabular}{|c|c|c|c|c|c|c|}
\hline Henan & 232 & 75 & 69 & 872 & 972 & 172 \\
\hline Hunan & 248 & 60 & 44 & 909 & 969 & 157 \\
\hline Fujian & 231 & 83 & 35 & 828 & 993 & 165 \\
\hline average & 231 & 84 & 57 & 721 & 980 & 300 \\
\hline
\end{tabular}

A statistical analysis of the amount of total cementitious materials in the average concrete mix proportion of each region is shown in Figure 1.

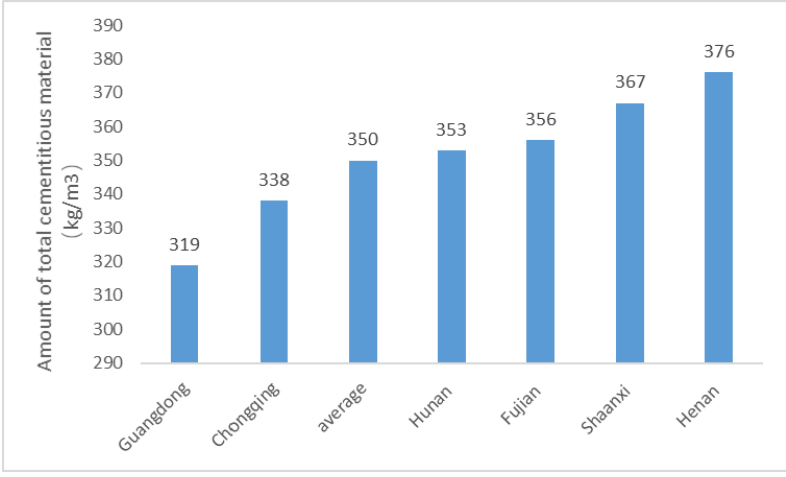

Fig. 1. The total amount of cementitious material in the average concrete mix in each region

It can be seen from Table 1 and Figure 1 that the total amount of cementitious materials in the concrete mix proportion in Guangdong is the lowest, which is the fundamental reason for the bleeding of concrete in this area. In the case of the same concrete strength level, the lower the amount of cementitious material in the concrete mix, the added water cannot be effectively absorbed and reacted by the cementitious material. The more free water, the greater the possibility of bleeding.

\subsection{Representative concrete mix proportion}

In this paper, 7 groups of $\mathrm{C} 30$ concrete mix proportions are selected for subsequent concrete tests, mainly the representative concrete mix proportions in Guangdong, Henan and Fujian, numbered PHB-1 PHB-7, and the concrete mix proportions are shown in Table 2.

Table 2. Representative concrete mix proportion

\begin{tabular}{|c|c|c|c|c|c|c|}
\hline \multirow{2}{*}{$\begin{array}{c}\text { Mix } \\
\text { proportion } \\
\text { number }\end{array}$} & \multicolumn{6}{|c|}{ Concrete mix proportion/ $\left(\mathrm{kg} / \mathrm{m}^{3}\right)$} \\
\hline & $\mathbf{C}$ & $\mathbf{F}$ & $\mathbf{K}$ & $\mathbf{S}$ & $\mathbf{G}$ & $\mathbf{W}$ \\
\hline PHB-1 & 100 & 100 & 100 & 780 & 1080 & 150 \\
\hline PHB-2 & 169 & 74 & 76 & 780 & 1067 & 157 \\
\hline PHB-3 & 135 & 100 & 80 & 780 & 1080 & 155 \\
\hline PHB-4 & 155 & 90 & 55 & 850 & 1060 & 150 \\
\hline
\end{tabular}

\begin{tabular}{|c|c|c|c|c|c|c|}
\hline PHB-5 & 200 & 60 & 60 & 790 & 1060 & 160 \\
\hline PHB-6 & 232 & 75 & 69 & 872 & 972 & 172 \\
\hline PHB-7 & 255 & 82 & 18 & 842 & 969 & 169 \\
\hline
\end{tabular}

\section{Remarks:}

PHB-1: C, F and K each 100 concrete mix proportion. PHB-2: Average concrete mix proportion of Guangdong.

PHB-3: Minimum cementconcrete mix proportion in Guangdong.

PHB-4: Lowest concrete mix proportion of total cementitious materials in Guangdong.

PHB-5: The highest cementconcrete mix proportion in Guangdong.

PHB-6: Average concrete mix proportion of Henan. PHB-7: Average concrete mix proportion of Fujian.

\subsection{Correlation analysis method}

Correlation analysis is an analysis method that describes whether there is a linear relationship between two variables, which is described by the correlation coefficient R. The characteristics of the correlation are reflected in two aspects, one is the direction (is it positive, negative or zero), and the other is the intensity (how close is it). The closer the absolute value of the correlation coefficient $|R|$ is to 1 , the higher the correlation between the two variables. The determination of the correlation includes the following:

(1) $|R|>0.95$ has a significant correlation;

(2) $|\mathrm{R}| \geq 0.8$ highly correlated;

(3) $0.5 \leq|\mathrm{R}|<0.8$ moderate correlation;

(4) $0.3 \leq|\mathrm{R}|<0.5$ low correlation;

(5) $|\mathrm{R}|<0.3$ The relationship is extremely weak and is considered irrelevant;

6) $\mathrm{R}=0$ is wirelessly related.

\subsection{Concrete test}

\subsubsection{Bleeding rate data}

In order to investigate the influence of different $\mathrm{C} 30$ mixing ratios $\mathrm{PHB}-1 \sim \mathrm{PHB}-7$ on the bleeding of concrete under low temperature environment, this paper chooses to use the same concrete raw materials under the low temperature environment of $15^{\circ} \mathrm{C}$, and adjust the content of polycarboxylate superplasticizer, Make the initial expansion of each mix proportion concrete at $550 \pm 20 \mathrm{~mm}$, and measure its normal pressure bleeding rate. The results of concrete bleeding rate with different mix proportions are shown in Table 3 .

Table 3. Results of concrete bleeding rate with different mix proportions

\begin{tabular}{|c|c|c|}
\hline $\begin{array}{c}\text { Mix } \\
\text { proportion }\end{array}$ & $\begin{array}{c}\text { Concrete mix proportion/ } \\
(\mathrm{kg} / \mathrm{m} 3)\end{array}$ & $\begin{array}{c}\text { Bleeding } \\
\text { rate } / \%\end{array}$ \\
\hline
\end{tabular}




\begin{tabular}{|c|c|c|c|c|c|c|c|}
\hline number & $\mathbf{C}$ & $\mathbf{F}$ & $\mathbf{K}$ & $\mathbf{S}$ & $\mathbf{G}$ & $\mathbf{W}$ & \\
\hline PHB-1 & 100 & 100 & 100 & 780 & 1080 & 150 & 9.1 \\
\hline PHB-2 & 169 & 74 & 76 & 780 & 1067 & 157 & 8.6 \\
\hline PHB-3 & 135 & 100 & 80 & 780 & 1080 & 155 & 7.1 \\
\hline PHB-4 & 155 & 90 & 55 & 850 & 1060 & 150 & 17.0 \\
\hline PHB-5 & 200 & 60 & 60 & 790 & 1060 & 160 & 15.8 \\
\hline PHB-6 & 232 & 75 & 69 & 872 & 972 & 172 & 3.8 \\
\hline PHB-7 & 255 & 82 & 18 & 842 & 969 & 169 & 4.2 \\
\hline
\end{tabular}

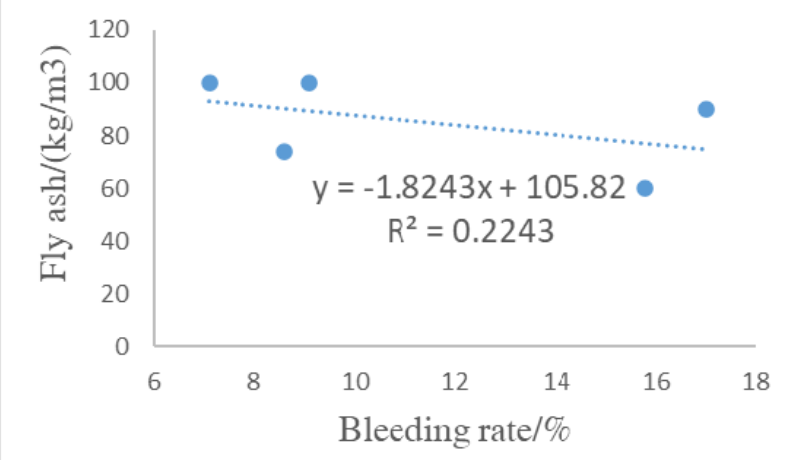

Fig.3. Correlation analysis between fly ash dosage and atmospheric bleeding rate

It can be seen from Figure 3 that the correlation coefficient R2 between the amount of fly ash and the bleeding rate is 0.2243 , and the $|R|$ value is 0.47 . According to the slope direction, the value of $\mathrm{R}$ can be judged to be negative, so $R$ is -0.47 , indicating the same design level The strength of the concrete mix, the amount of fly ash and the bleeding rate of concrete are lowly related.

The correlation analysis between the amount of slag powder and bleeding rate is performed, and the results are shown in Figure 4.

in Guangdong, and the total amount of cementing materials is equivalent. Correlation analysis of the cement dosage, fly ash dosage, and slag dosage of these mix proportions and bleeding rate were carried out. The results are shown in Figure 2 to Figure 4, and Figure 2 is the correlation analysis between cement dosage and bleeding rate.

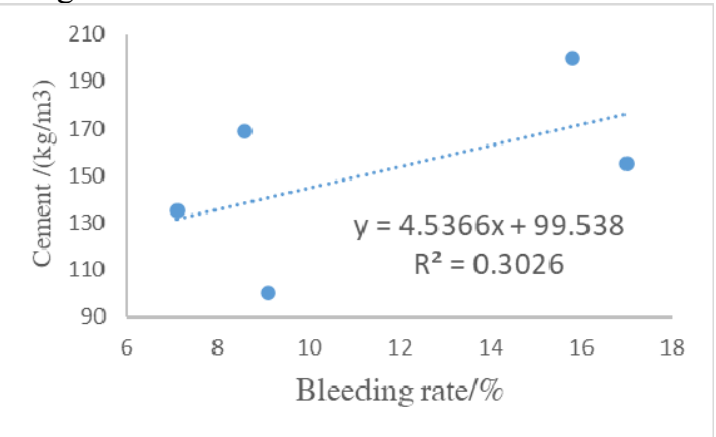

Fig. 2. Correlation analysis between cement dosage and bleeding rate

It can be seen from Figure 2 that the correlation coefficient $\mathrm{R} 2$ between cement dosage and bleeding rate is 0.3026 . According to the slope direction, the value of $\mathrm{R}$ can be judged to be a positive value, so $\mathrm{R}$ is 0.55 , indicating the mix proportion of concrete with the same level of strength, cement dosage and bleeding rate It is moderately relevant.

The correlation analysis between the amount of fly ash and bleeding rate is performed, and the results are shown in Figure 3.

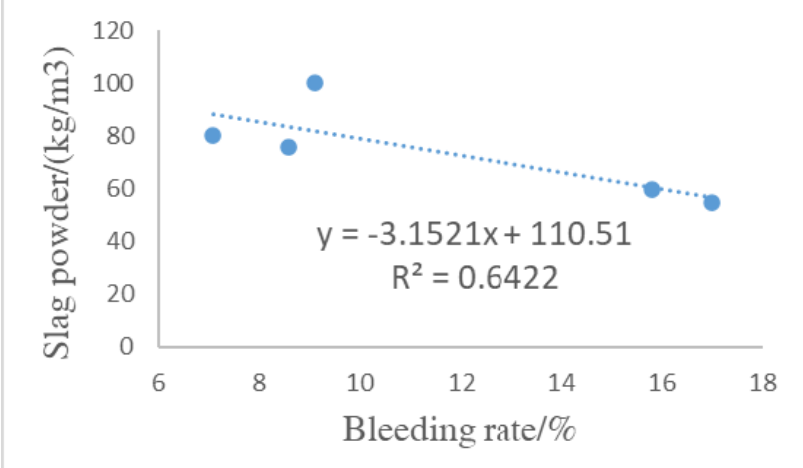

Fig. 4. Correlation analysis between slag powder dosage and bleeding rate

It can be seen from Figure 4 that the correlation coefficient R2 between the amount of slag powder and the bleeding rate is 0.6422 , and the $|R|$ value is 0.80 . According to the slope direction, the value of $\mathrm{R}$ can be judged to be negative, so $\mathrm{R}$ is -0.80 , indicating that the design has the same grade strength For the concrete mix proportion, the amount of slag powder is highly correlated with the bleeding rate of concrete, and as the amount of slag powder increases, the bleeding rate of concrete is lower.

The correlation analysis between the total amount of gelling materials of PHB-1 to PHB-7 and the bleeding rate was carried out, and the results are shown in Figure 5. 


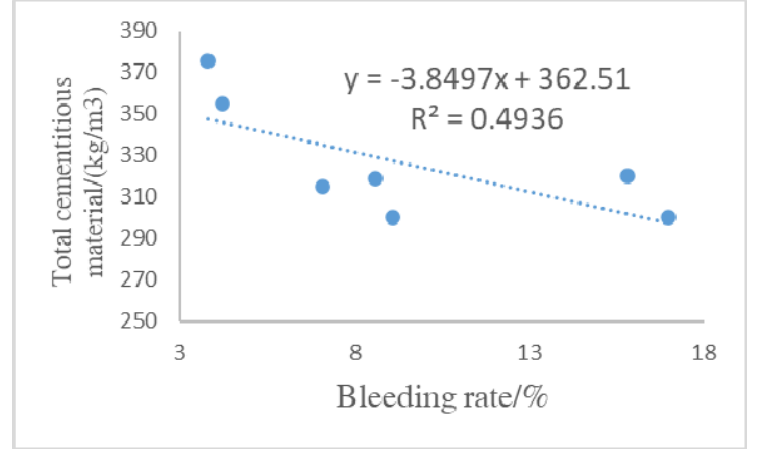

Fig. 5. Correlation analysis between total amount of cementitious material and bleeding rate

It can be seen from Figure 5 that the correlation coefficient R2 between the total amount of gelling material and the bleeding rate is 0.4936 , and the $|R|$ value is 0.70 . According to the slope direction, the value of $R$ can be judged to be negative, so $\mathrm{R}$ is -0.70 , indicating the same design For grade-strength concrete mix proportion, the total amount of cementitious material is moderately related to the bleeding rate of concrete, that is, as the total amount of cementitious material increases, the bleeding rate of concrete decreases.

\section{Conclusion}

Aiming at the problem of $\mathrm{C} 30$ concrete bleeding in winter in Guangdong, this article starts from the direction of mix proportion and collects the mix proportion of $\mathrm{C} 30$ concrete in 6 regions of Guangdong, Fujian, Henan, Hunan, Chongqing and Shaanxi. 70 mix proportions were collected from each region, and concrete bleeding tests were carried out for the representative concrete mix proportions in Guangdong Province. The contents and results of the study showed:

(1) Compared with $\mathrm{C} 30$ concrete mix proportions in other regions, the total amount of cementitious materials in the concrete mix proportions in Guangdong is the lowest, which is the root cause of concrete bleeding in this area.

(2) For the concrete mix proportion of the same grade of strength and the same amount of cementitious materials, the amount of cement is moderately related to the bleeding rate of concrete, the amount of fly ash is lowly related to the bleeding rate of concrete. And the amount of slag powder is highly correlated with the bleeding rate of concrete.

(3) For the concrete mix proportion of the same grade of strength, the total amount of cementitious material has a moderate correlation with the bleeding rate of concrete.

(4) The effect of different amounts of cementitious materials on the bleeding rate of concrete is arranged in descending order: the amount of slag powder $>$ the total amount of cementitious materials $>$ the amount of cement $>$ the amount of fly ash. That is, with the increase of the total amount of cementitious materials and the amount of slag powder, the lower the bleeding rate of concrete.

\section{References}

1. L.T. Guo, J.Water Resources and Architectural Engineering, 5 (2010)

2. B.D. Luo, Water Transport Engineering, 3 (2009)

3. L.B. Xu, Concrete, 1 (2015)

4. S. Xie, Engineering Construction and Design, 2 (2020)

5. M. J. Shannag, Cement\&Concrete Composites, 22 (2000)

6. H. Beshr, A. A. Almusallam, M. Maslehuddin, Construction and Building Materials, 17 (2003) 